\title{
Observations and source investigations of the boundary layer bromine monoxide (BrO) in the Ny-Ålesund Arctic
}

\section{Yuhan Luo et al.}

Correspondence to: Yuhan Luo (yhluo@aiofm.ac.cn) and Fuqi Si (sifuqi@aiofm.ac.cn)

The copyright of individual parts of the supplement might differ from the CC BY 4.0 License. 
Fig S1. Ensemble back trajectory calculations of air masses arriving at Ny-Alesund from 22 April 00:00 UTC to 30 April 00:00 UTC at sea level. Each trajectory runs 72 hours.
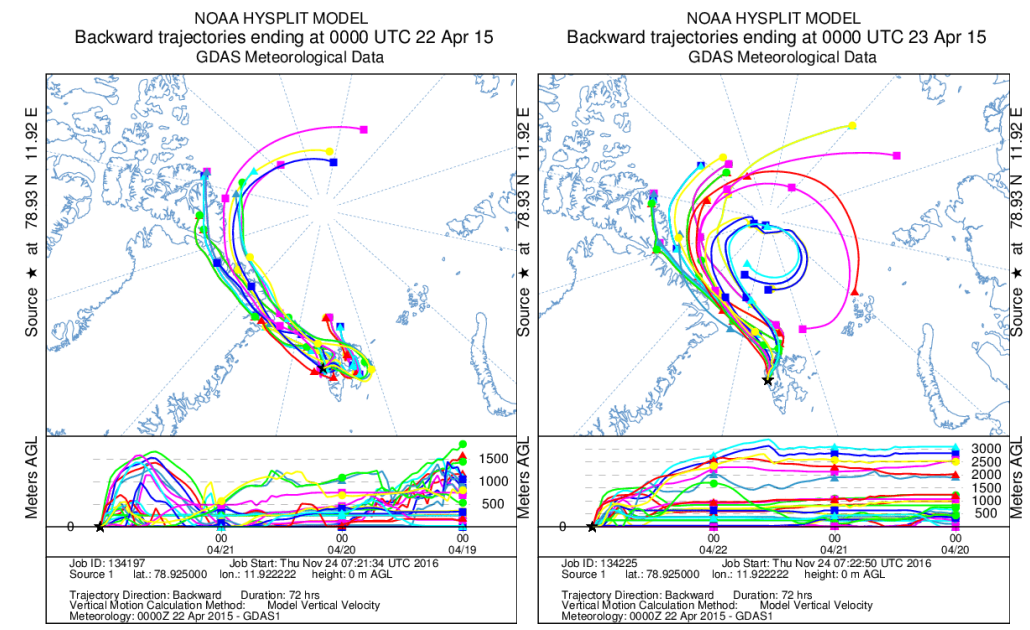

Backward trajectories ending at 0000 UTC 24 Apr 15

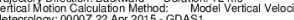
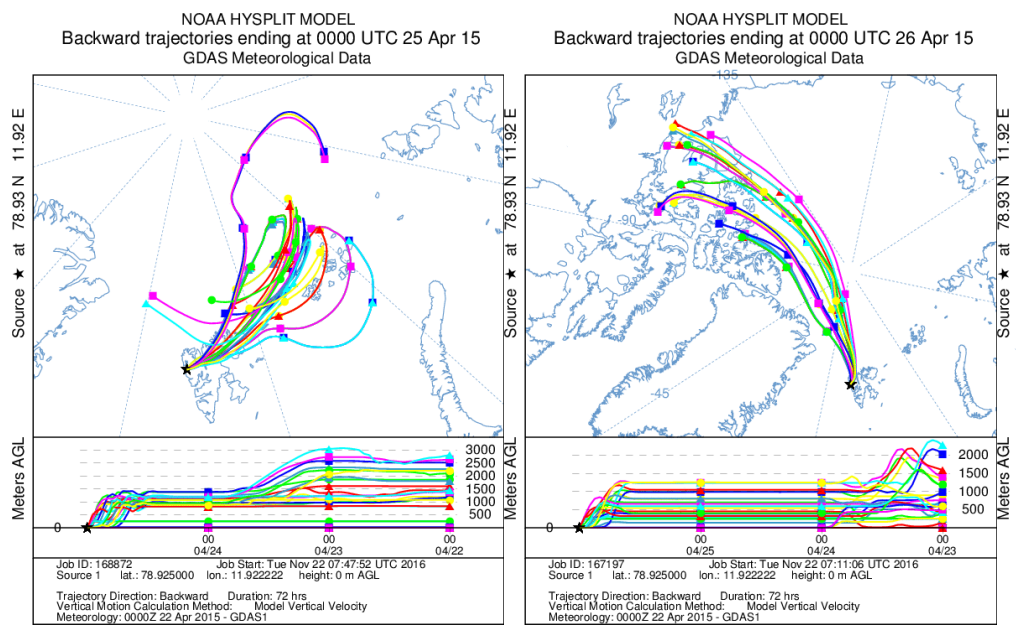

Backward trajectories ending at 0000 GDTC

5

NOAA HYSPLIT MODEL

Backward trajectories ending at 0000 UTC 28 Apr 15 DAS Meteorological Data
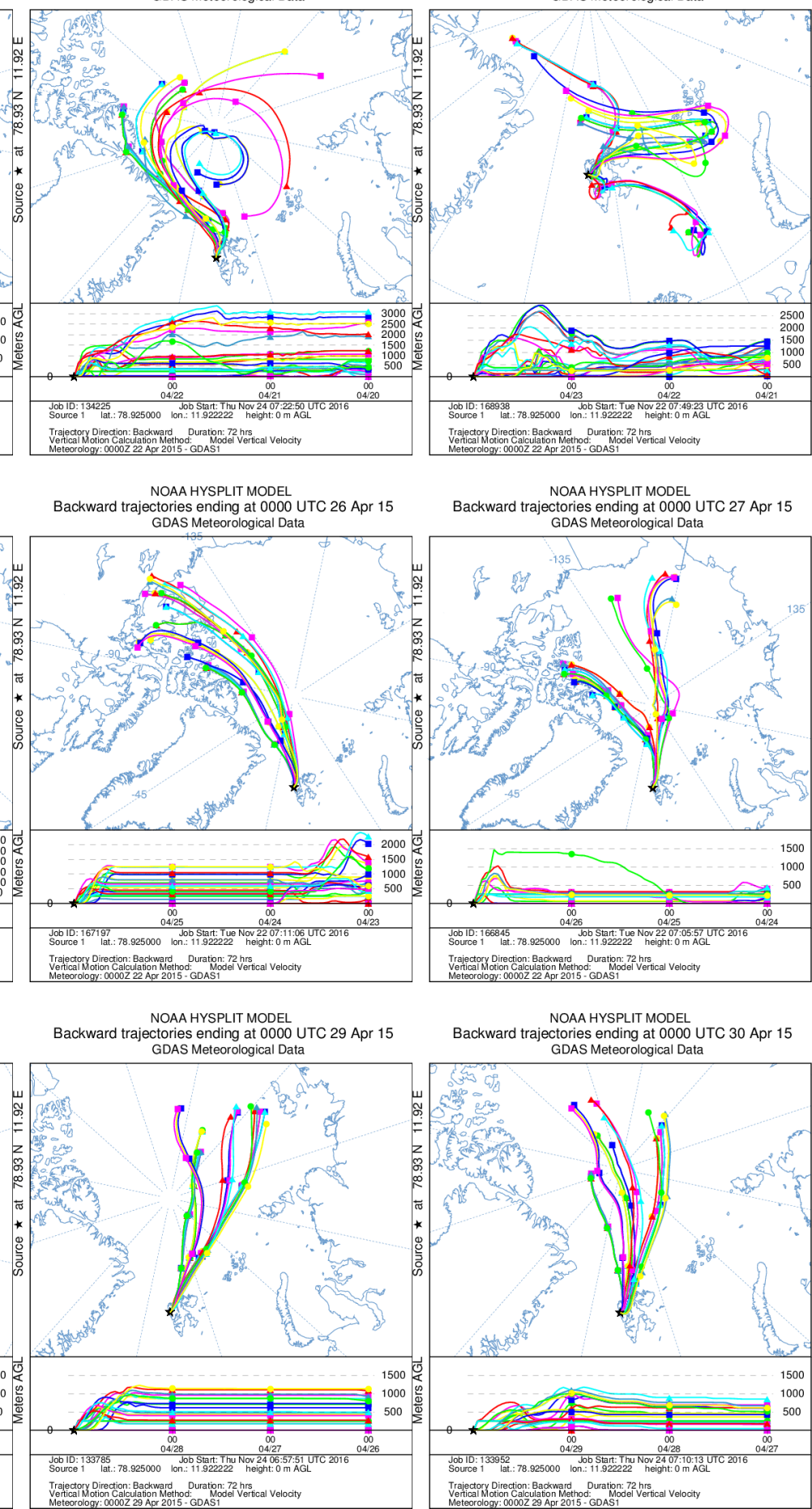

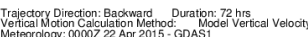
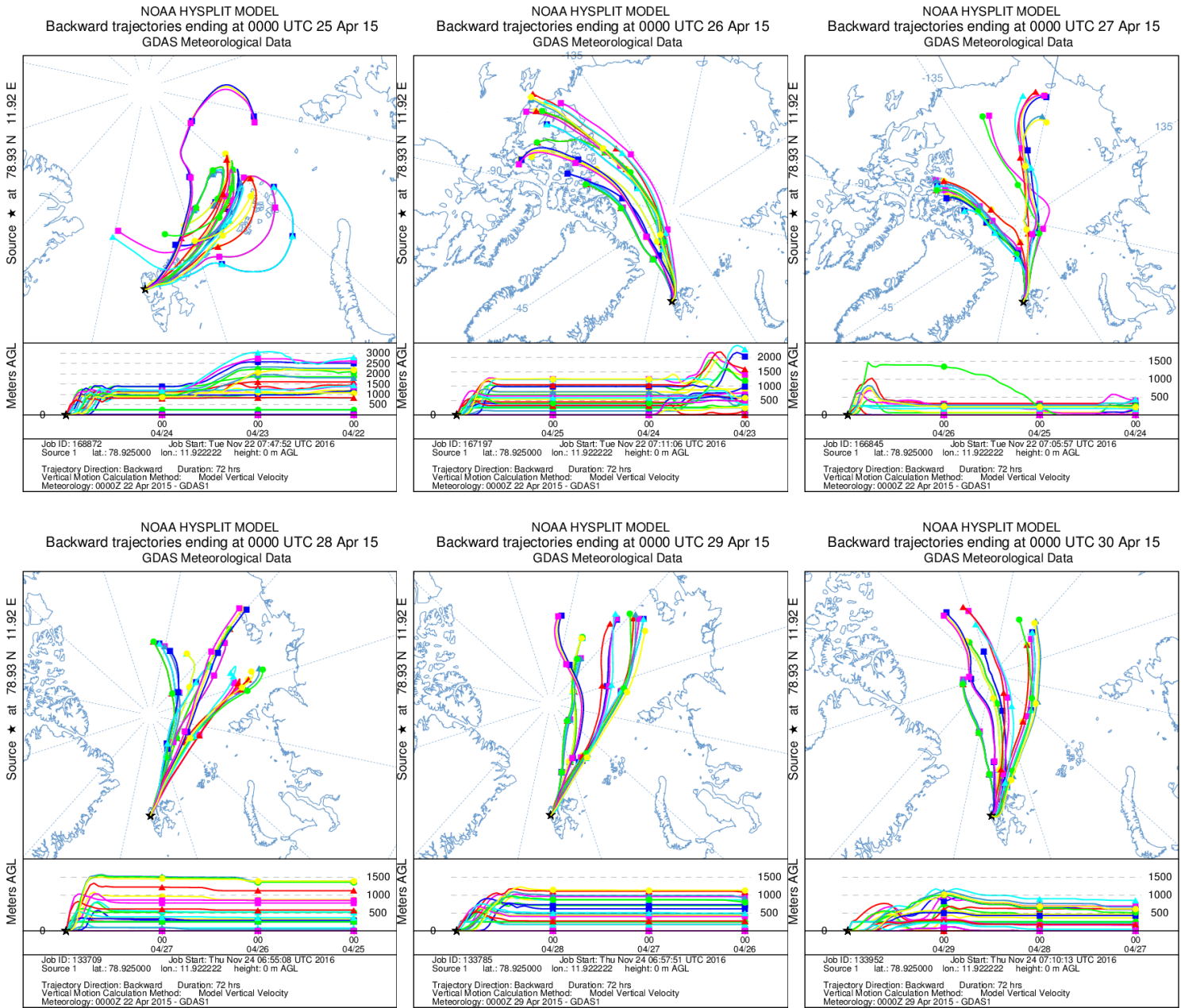

NOAA HYSPLIT MOD ories ending at 0000 UTC 30 Apr 15

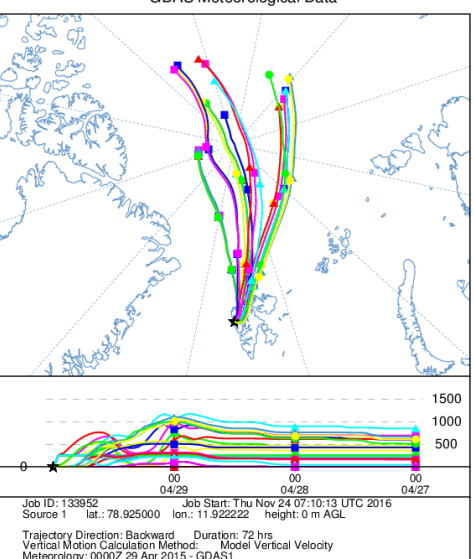


Fig S2. Ensemble back trajectory calculations of air masses arriving at Ny-Alesund from 22 April 00:00 UTC to 30 April 00:00 UTC at 500 meters a.s.l. Each trajectory runs 72 hours.
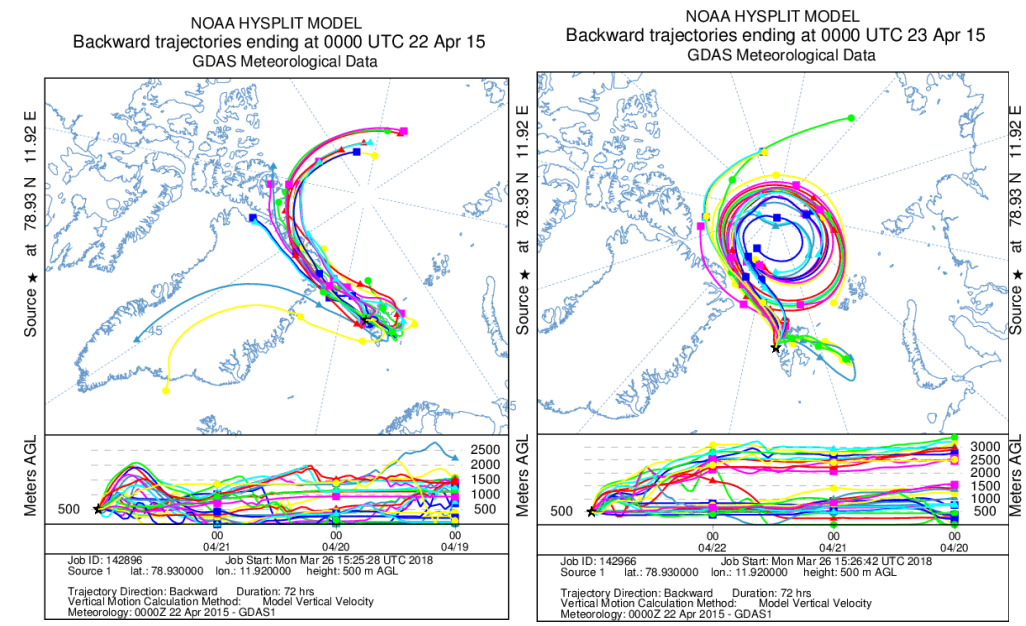

NOAA HYSPLIT MODEL
Backward trajectories ending at 0000 UTC 24 Apr 15

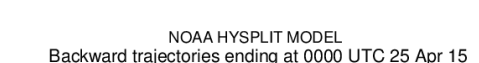

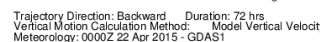
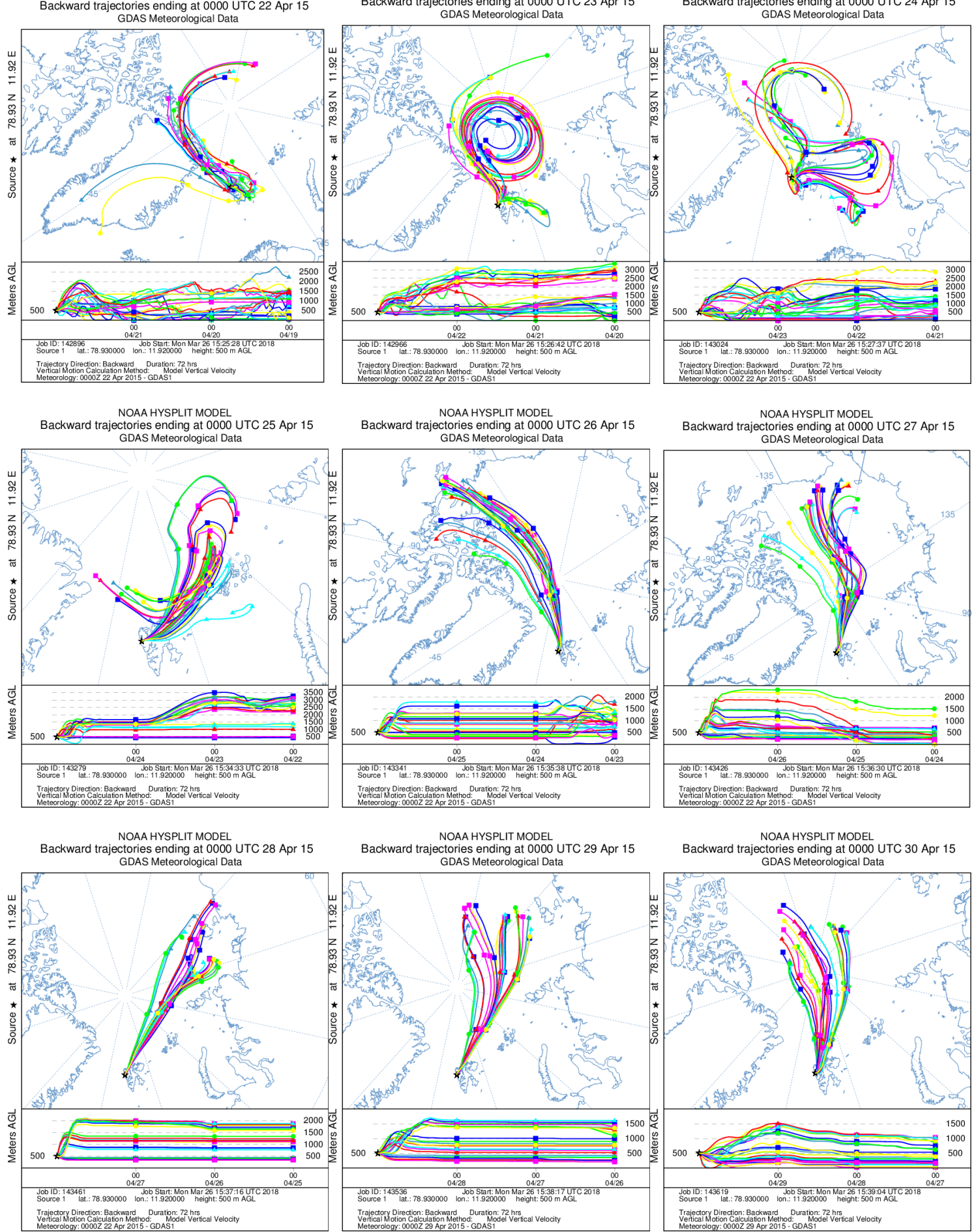
Fig S3. Maps of troposphere BrO of northern hemisphere by GOME-2 product from 20 April to 13 May. (Cited from

\section{http://www.iup.uni-bremen.de/doas/scia_data_browser.htm)}

BrO clouds existed at two main periods: coastal North America and Chukchi Sea during 22-23 April and North of Siberia during 08-11

May 2015. Both of the BrO clouds lasted about three to four days, the first of which was occasionally at the same period with the 5 Ny-Ålesund $\mathrm{BrO}$ enhancement event.

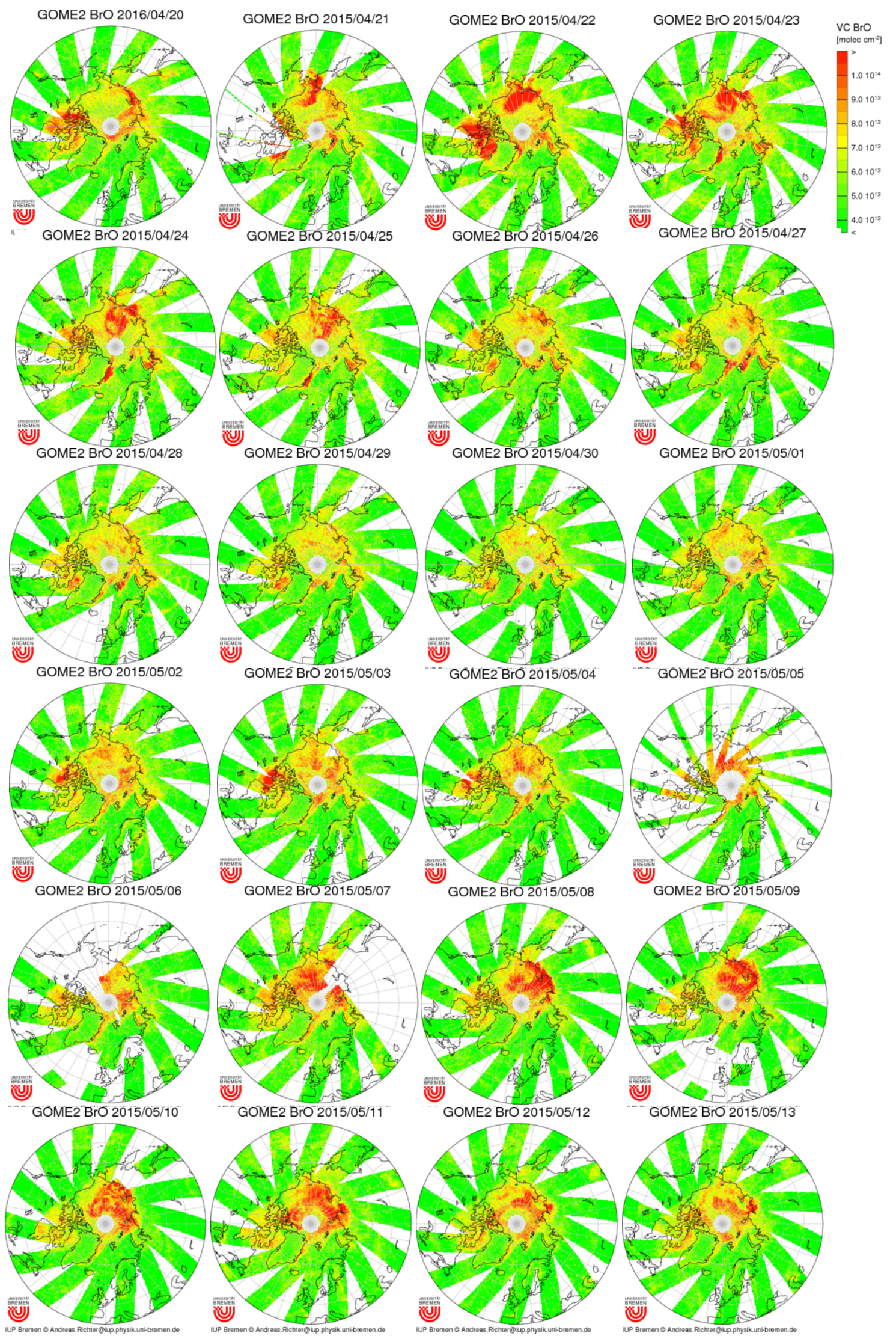

